\title{
INEQUALITY PERSISTENCE THROUGH VERTICAL VS. HORIZONTAL COALITIONS
}

\author{
MIQUEL PELLICER-GALLARDO
}

\begin{abstract}
This paper aims at contributing to explain the observed high persistence of cross country differences in inequality and levels of redistribution. It focusses on the interactions between inequality and the predominance of either horizontal coalitions (i.e. among individuals of similar economic status) or vertical ones (among individuals with different economic status). The paper shows that the interactions between inequality and the type of coalition formed in a society can give rise to self-sustained social contracts where inequality persists: because the poor take time to organize, when inequality is high, the poor are particularly vulnerable to consumption fluctuations and are willing to give up substantial redistribution in order to be protected from these. For the rich, this "traditional social contract" is an investment. If the rate of return to alternative investments rises substantially or the elite becomes weakened, this traditional social contract may break, paving the way for working class organization and a permanent decrease in inequality. Differences in inequality between Latin America (and the Middle East) and contemporary Western Europe are discussed in the light of the model. The European transformation in inequality, redistribubtion and social relations in Modern times is also discussed focusing on England.
\end{abstract}

\section{INTRODUCTION}

Differences in levels of inequality are remarkably persistent across countries and broad world regions. Latin America and parts of Africa come to mind as traditionally high inequality regions, compared to, say, Western Europe and South East Asia, and remain largely so still today. From the 70 s to the 90 s, for instance, the average decadal Gini coefficient in Latin America ranged from 48.8 to 52.2. For Asia the range is between 40.2 and 41.2 , while for Eastern Europe, the figures are 32.3 and 34.2 (De Ferranti et al. (2003)). A similar picture emerges using data extending further back into the past. Data recently compiled by Frankema (2006), on land inequality stretching over the whole XXth century, shows Latin American Gini coefficients (averaged over quarters of a century) ranging between 76.6 and 77.9. The figures for Asia are, in contrast, 47.6 and 48.0. The small across-time variation within regions contrasts strikingly with the wide differences across regions, revealing a substantial degree of inequality persistence.

This paper proposes a novel political economy mechanism that can help explaining why differences in inequality tend to be so persistent across countries. The mechanism proposed is based on the type of coalitions different agents choose to form. In particular, it hinges on whether poor agents (or citizens) tend to organize horizontally (i.e. among themselves) or form a coalition with the elite (i.e. a vertical coalition). The paper argues that coalitions arising when inequality is high will 
tend to redistribute less and vice versa. In that way, it makes a case for regarding the type of coalition formed as an element contributing to inequality persistence.

The importance of the type of coalition formed for the dynamics of inequality has been recently put forward in De Ferranti et al. (2003). Studying the reasons for the persistently high inequality observed in Latin America, the authors emphasize the prevalence of vertical coalitions in the region. Other studies hint at the likely relevance of these forces from a historical perspective. Acemoglu and Robinson (2000), Justman and Gradstein (1999) and Lindert (2004) emphasize the importance of political voice for the dynamics of redistribution and inequality. In particular, they argue that the transition towards the comparatively low degree of inequality observed in European countries starting around the beginning of the twentieth century is related to the increasing political voice of the poor segments of society. To the extent that these, and other studies, link increasing political voice (particularly through franchise extension) to the revolutionary threats imposed by the poor, the importance of horizontal organization for redistribution and inequality is warranted. ${ }^{1}$ All these studies thus point at the relevance of horizontal coalitions for explaining observed degrees of inequality. In order for this mechanism to account for its persistence, however, the (reverse) link between inequality and the type of coalition formed needs to be incorporated into the analysis.

This paper studies these two-way interactions between inequality and the choice of horizontal vs. vertical coalitions by developing a simple two-period model. In the model, there are two types of individuals, rich and poor, who produce, save and consume. Rich individuals have access to a technology that yields positive returns to their savings ${ }^{2}$. In this context, individuals may form horizontal or vertical coalitions. A horizontal coalition yields exogenously given redistribution levels and takes time to build. Thus, it leads to redistribution of resources from the rich to the poor only in the second period; in the first period, before the poor have had time to organize, the opposite may even occur. Redistribution levels in a vertical coalition, in contrast, are chosen by the elite, and can be implemented immediately. This setting seems plausible in societies where the local dimension in politics is prominent, as is the case in many preindustrial or industrializing societies. Then, the local elites can easily "buy off" the local population while global horizontal coalitions are particularly difficult to build. More generally, coordination problems for agreeing on agendas, leadership, etc. seem more acute in horizontal coalitions rather than in vertical ones, thus justifying that a horizontal coalition brings benefits for the poor only in the long run, and may even carry costs in the short run.

This setting gives rise to insights of some generality. A vertical coalition may arise because the poor are willing to give up redistribution in exchange for smoothing consumption fluctuations over time. Redistribution is thus lower in a vertical coalition. Moreover, due to Decreasing Absolute Risk Aversion (DARA) utility, the poor are more vulnerable to consumption fluctuations the poorer they are. Thus, the rich are willing to engage in a vertical coalition only when the poor are sufficiently poor; i.e. when inequality is sufficiently high. In this way, the model captures neatly that the vertical coalition is an investment for the elite. The model

\footnotetext{
${ }^{1}$ Besides the aforementioned studies, Conley and Temimi (2001) and Jack and Lagunoff (2004) also stress the importance of revolutionary threats by the poor for franchise extensions.

${ }^{2}$ The fact that only the rich have access to this technology can be rationalized by fixed costs preventing the poor for undertaking the investment.
} 
is extended to account for inequality dynamics. Two stable inequality steady states may arise: high inequality perpetuates through the formation of a vertical coalition, which leads to little redistribution while low inequality perpetuates through a highly redistributive horizontal coalition. The high inequality steady state fails to exist if returns to alternative investments (here, returns to savings) are sufficiently high, as the investment in the vertical coalition becomes less attractive for the rich.

The paper discusses briefly differences in inequality between contemporary Western Europe on the one hand, and Latin America and the Middle East on the other, in the light of the model proposed. The West European transition from high to low inequality around the beginning of the XXth century is also discussed, focusing on the experience of England.

The paper is organized as follows. Section 2 presents the model and derives the type of coalition chosen for different levels of inequality as well as the equilibrium relation between inequality and redistribution. The dynamics of inequality are subsequently analyzed. Section 3 discusses briefly, in the light of the model, differences in inequality across certain regions of the world as well as its development in Western Europe, focusing on England. Finally, Section 4 provides some concluding remarks.

\section{Related Literature}

A particularly relevant piece in the understanding inequality persistence is the relationship between inequality and redistribution. To the extent that inequality is negatively related to redistribution, inequality differences are likely to persist. This is not, however, the standard political economy view on this relationship. The standard story essentially argues that more unequal societies ought redistribute more, since the median voter tends to be poorer relative to the mean (see, for instance, Meltzer and Richards (1981), Persson and Tabellini (1994) and Alesina and Rodrick (1994)). This view has been increasingly challenged for its lack of empirical support. Even if no consensus has yet emerged, empirical studies increasingly find that more unequal societies tend to redistribute less, not more, both when comparing across countries and over time (see Lindert (2004) and De Mello and Tiongson (2003)). As a result, several alternative mechanisms have been proposed in the literature, yielding a negative relationship between inequality a redistribution (Benabou (2000), Saint Paul (2001), Rodriguez (2004). See also Saint Paul and Verdier (1996)). This paper points at an additional channel through which inequality may be negatively related to redistribution: the type of coalition that prevails in a society.

A second important type of literature this paper relates to, is the recent literature on co-optation. Bertocchi and Spagat (2001), and the broader studies on regime-opposition interactions in authoritarian regimes, such as Wintrobe (1998) and Bueno de la Mesquita et al. (2003), all point at the importance of the cooptation of the opposition for authoritarian regime survival or its demise. Unlike all these studies, this paper bring inequality directly into the picture, studying the two-way interactions between inequality and the degree of co-optation of the population. Furthermore, using a two-period model and allowing for a more realistic (curved) utility function, this paper is able to cleanly characterize co-optation as an investment for the elite, and hence extract implications regarding rates of return to alternative investments. 
Besides these strands of literature, this paper is related to two other types of literature. One is the literature studying demand for redistribution in modern societies and the traditional puzzle of why the poor do not expropriate the rich in democracies (see Putterman, Roemer and Silvestre (1998)). The present paper argues that the poor may be willing to give up redistribution in exchange for consumption smoothing if horizontal organization takes time to yield results. ${ }^{3}$ A final strand of related literature is the emerging literature on franchise extension, particularly those models emphasizing the threat of revolution in the extension of the suffrage (see above). The important contributions of Acemoglu and Robinson to this literature hinge crucially on the assumptions that revolutionary opportunities for the poor are temporary and that these opportunities arrive exogenously. As the authors themselves acknowledge, the arrival of these opportunities are related to, among others, the level of organization of civil society. Indeed, the fact that serious revolutionary threats were relatively absent from Western Europe before the XVIIIth century can hardly be considered random. The model in this paper, while not considering franchise extension as such, yields additional insights into the problem by endogeneizing the choice of organization of the poor and analyzing its relation to inequality.

\section{The Model}

3.1. Environment. Consider a two-period economy with a continuum 1 of agents. A proportion $\lambda$ of these agents are poor and the remaining, $(1-\lambda)$, are rich, where $\lambda>\frac{1}{2}$. Individuals are born endowed capital, which, in this economy, represents physical capital, human capital, land, or a mix of the three. In particular, poor and rich individuals are endowed with $k_{P}$ and $k_{R}$ units of capital, respectively, where $k_{P}<k_{R}$. Agents live for two periods. In each period, capital is used to produce a consumption good $y$ according to a linear technology, which is assumed to take the simple form $y^{i}=k^{i}$, for $i=P, R$. Production at the end of the first period can be saved or consumed. It is assumed that savings yield a higher returns for rich than for poor individuals. For simplicity, it assumed that returns for the rich equal $B_{R}>1$ while those for the poor equal $B_{P}=1$. This assumption can be thought of as capturing the presence of some fixed cost that prevent the poor from undertaking investment opportunities. Finally, individuals derive utility from consumption at the end of each period. For simplicity, the utility function is assumed to be logarithmic and the time discount factor is assumed to equal one.

The poor have the opportunity to force redistribution of assets $k$. Doing so, however, requires building a coalition among themselves; i.e. a horizontal coalition. It is assumed that a horizontal coalition can only force asset redistribution from the rich to the poor in the second period. This critical assumption captures the idea that horizontal organization takes time to form, possibly for coordination problems. Before the poor have organized (i.e. in the first period), the rich are able to extract a proportion $\mu$ of the wealth of the poor. Once the poor are organized, in the second period, total assets are divided between the poor and the rich according to the proportions $\theta$ and $1-\theta$, respectively. It is assumed that $\mu<\frac{\theta}{\lambda}$; i.e that in the second period, each poor displays more post-redistribution resources than in the

\footnotetext{
${ }^{3}$ Bertola and Koeniger (2005) also relate consumption smoothing to demand for redistribution by arguing that credit constraints enhance the demand for redistribution by tempering the relative value of future upward mobility.
} 
first. Notice that, if $\theta=\lambda$, assets are completely equalized across the population in a second period with a horizontal coalition. From the above, the value functions for each group in case of a horizontal coalition, $U_{i}^{H}$, equal:

$$
\begin{aligned}
U_{P}^{H} & =\underset{S}{M a x} \log \left(\mu k_{P}-S_{P}\right)+\log \left(\frac{\theta}{\lambda} \bar{k}+S_{P}\right) \\
U_{R}^{H} & =M_{S} a x \log \left(k_{R}+\frac{\lambda}{1-\lambda}(1-\mu) k_{P}-S_{R}\right)+\log \left(\frac{1-\theta}{1-\lambda} \bar{k}+B_{R} S_{R}\right)
\end{aligned}
$$

where $\bar{k}=(1-\lambda) k_{R}+\lambda k_{P}$.

In order to prevent forced redistribution, the rich may offer the formation of a vertical coalition. In a vertical coalition, the rich offer resources in order to limit the extent of future redistribution. Crucially, a vertical coalition allows for an immediate transfer of resources where each poor receives $\frac{1}{2} T$. Due to commitment problems, however, transfers in a vertical coalition cannot be intertemporally tailored: all transfers need to be done in the first period. These capital transfers are kept for the two periods so that each poor effectively receives an amount $T$ of transfers over her lifetime. Thus, the corresponding value functions are

$$
\begin{aligned}
& U_{P}^{V}=\operatorname{Max}_{S} \log \left[\left(k_{P}+\frac{T}{2}\right)-S\right]+\log \left[\left(k_{P}+\frac{T}{2}\right)+S\right] \\
& U_{R}^{V}=M_{S} a x \log \left[\left(k_{R}-\frac{\lambda}{1-\lambda} \frac{T}{2}\right)-S\right]+\log \left[\left(k_{R}-\frac{\lambda}{1-\lambda} \frac{T}{2}\right)+B_{R} S\right],
\end{aligned}
$$

The timing of the model is as follows. First, the rich decide whether to offer or not the formation of a vertical coalition and, if so, the amount of transfers associated to it. Then, the poor decide whether to reject or accept the offer. The corresponding asset transfers or (regressive) redistribution take place. With those, agents produce and take their savings / consumption decisions and the first period ends. In the second period, (progressive) redistribution occurs in the case of a horizontal coalition. Agents then produce while the rich obtain the returns from their investment. Finally, agents consume all their income and die.

Capital markets play a key role in this model in one single respect: it is assumed, plausibly, that in case of a horizontal coalition, borrowing against future redistribution is not permitted. Besides this case, all optimal savings decisions will be non-negative.

It is worth stressing that redistribution in this model is restricted to assets. In particular, savings and the income accruing from them are not subject to redistribution. In this sense, this model can be well suited to analyze situations such as mostly agricultural societies - where the main distributional conflict is land but where the elite is engaged additionally in mercantilist or capitalist activities - as well as modern developing economies where the elite is able to invest abroad.

3.2. Inequality, Coalitions and Redistribution. The model is solved by backward induction. The savings decisions are solved in the first place, leading to indirect utility functions. Second, the minimum transfer required for the poor to accept the vertical coalition is derived, for each level of inequality. Finally, for each level of inequality, the equilibrium coalition and the amount of transfers is then determined by the choices of the rich. 
Consider first the options of the poor individuals. Their savings decisions are straightforward: In the vertical coalition, since income in the first and second periods is the same and since savings give return equal to unity, the optimal choice is to save exactly zero. In the horizontal coalition, in contrast, future redistribution gains make income higher in the second than in the first period. Thus, optimal savings, if unconstrained, would be negative. Since borrowing against future redistribution is not allowed by assumption, optimal savings will be also zero. The indirect utility functions for the poor can thus be directly written.

It will prove useful to normalize all variables by the average capital $\bar{k}$. As will become clear below, doing so will leave all relevant expressions as a function of $\frac{k_{P}}{\bar{k}}$, which will be denoted simply by $k \in(0,1)$, and will be the measure of equality used. Likewise, total transfers in a vertical coalition normalized by average capital $\frac{T}{\bar{k}}$ will be denoted by $t$. In that way, the value functions of the poor in the horizontal and the vertical coalitions become, respectively:

$$
\begin{aligned}
U_{P}^{H} & =\log \mu k \frac{\theta}{\lambda} \bar{k}^{2} \\
U_{P}^{V} & =\log \left(k+\frac{t}{2}\right)^{2} \bar{k}^{2}
\end{aligned}
$$

The minimum transfers required for poor individuals not to engage in a horizontal coalition can now be derived. Equalizing (1), and (2) yields

$$
t^{V}=\left(\mu k+\frac{\theta}{\lambda}-2 k\right)-\left(\sqrt{\frac{\theta}{\lambda}}-\sqrt{\mu k}\right)^{2}
$$

This expression has a simple interpretation. The first term, $\left(\frac{\theta}{\lambda}+\mu k-2 k\right)$, is the total redistribution received by each poor agent in the event of a horizontal coalition, normalized by average capital (call it $t^{H} \equiv \frac{\mu k_{P}+\frac{\theta}{\lambda} \bar{k}-2 k_{P}}{\bar{k}}$ ). The second term, $\left(\sqrt{\frac{\theta}{\lambda}}-\sqrt{\mu k}\right)^{2}$, is the distance between consumption in the two periods with a horizontal coalition - again normalized by average capital. Thus, it represents the costs of horizontal organization due to its lack of inter-temporal consumption smoothing.

Expression 3 shows directly that the poor are willing to give up redistribution in order to smooth consumption. The second term in the expression, moreover, makes clear that the poorer they are, the more redistribution they are willing to give up in order to avoid consumption fluctuations over time. This is because log utility exhibits Decreasing Absolute Risk Aversion, whereby aversion to additive fluctuations decreases with wealth. This feature of the utility function is broadly consistent with the observed attitudes towards risk (see Gollier (2001)) and captures the idea that poorer individuals are more vulnerable to consumption fluctuations.

Given the minimum transfers just derived, the rich decide whether to offer a vertical coalition or not by comparing the value they obtain from the two types of coalitions. Deriving the standard first order conditions for savings, normalizing by average capital, substituting $t^{V}$ in 3 in the vertical coalition and rearranging in order to highlight their common structure, the following indirect utility functions are obtained: 


$$
\begin{aligned}
U_{R}^{H} & =\log \left(\chi\left(1-\lambda \frac{\frac{\theta}{\lambda}+\mu B_{R} k}{1+B_{R}}\right)\right)^{2} \\
U_{R}^{V} & =\log \left(\chi\left(1-\lambda \sqrt{\mu k \frac{\theta}{\lambda}}\right)\right)^{2}
\end{aligned}
$$

where $\chi \equiv \frac{1+B_{R}}{2 \sqrt{B_{R}}} \frac{1}{1-\lambda} \bar{k}$.

It is now possible to derive the equilibrium coalition in this economy as a function of inequality by comparing 4 , and 5 . The following proposition states the corresponding results:

Proposition 1. The equilibrium coalition depends on inequality in the following way:
a) if $k>k^{*} \equiv \frac{\theta}{\lambda \mu} \frac{1}{B_{R}^{2}}$,
the Horizontal Coalition is chosen
b) otherwise,
the Vertical Coalition is chosen

Proof. Just compare 4 and 5

Proposition 1 makes two relevant points. First, in this model the horizontal coalition arises only when the economy is sufficiently equal. From DARA utility, as the poor become poorer, they become more vulnerable to consumption fluctuations and are willing to give up more future redistribution in exchange for inter-temporal consumption smoothing. This makes a vertical coalition worth for the rich only when inequality is sufficiently high.

A second set of relevant results from Proposition 1 regards the inequality thresholds separating each coalition. First, a vertical coalition is less likely the higher is the rate of return on savings $B_{R}$. In this model, a vertical coalition is, for the rich, an investment: it implies giving up resources now in the form of transfers in exchange for reductions in redistribution in the future. As the rate of return on other investment rises, savings in the first period become more valuable, and make the investment in the vertical coalition relatively less attractive. The opposite occurs the more important worker organization is for redistribution. If the gains that the poor obtain in a horizontal coalition once they are organized (in the second-period) $\frac{\theta}{\lambda}$ rise relative to what they can keep while they are not (in the first period) $\mu$, the vertical coalition becomes more likely. This is because the horizontal coalition becomes less attractive for the poor, since it worsens the inter-temporal consumption fluctuations.

3.3. Inequality Dynamics and Steady States. The essentially negative relationship between inequality and redistribution through the type of coalition formed (high inequality - vertical coalition - low redistribution and vice versa) hints at the possibility of multiple steady states. In order to cleanly illustrate the dynamics of inequality and redistribution in this model, I consider the simplest possible inter-generational transmission of resources. In particular, each individual has one offspring, which inherits the capital that her parent owned when old (i.e. in the second period). 
The evolution of inequality over time is determined by $k_{t}$ which is, as before, the capital of poor individuals normalized by average capital. In this way, the dynamics of inequality are characterized by the following equation in differences:

$$
k_{t+1}=f\left(k_{t}\right)=\left\{\begin{array}{l}
\sqrt{\mu k_{t} \frac{\theta}{\lambda}} \text { if } k_{t}<\frac{\theta}{\lambda \mu} \frac{1}{R^{2}} \\
\frac{\theta}{\lambda} \quad \text { otherwise }
\end{array}\right.
$$

The function $f\left(k_{t}\right)$ is a piece-wise defined function where each "piece" corresponds to the type of coalition emerging from a given degree of inequality $k_{t}$ (as stated in Proposition 1). If inequality is high $\left(k_{t}<\frac{\theta}{\lambda \mu} \frac{1}{R^{2}}\right)$, a vertical coalition is formed and the offspring of a poor individual inherits the parent's capital plus the transfers; normalized by average capital to obtain our measure for inequality and substituting for the equilibrium value of transfers in the vertical coalition (in 3) yields $\sqrt{\mu k_{t} \frac{\theta}{\lambda}}$. Otherwise, if inequality is low, the poor offspring inherits the second period outcome from a horizontal coalition, which, again normalized, yields simply $\frac{\theta}{\lambda}$. Taking as given an arbitrary level of inequality at time zero $k_{0} \neq 0$, these expressions fully characterize the dynamics of inequality in this model. The following proposition states the corresponding results.

Proposition 2. 1) If $\mu R>1$, inequality converges to a unique stable steady state where the coalition is horizontal and where asset inequality equals $\bar{k}_{S}=\frac{\theta}{\lambda}$.

2) If $\mu R<1<\mu R^{2}$, there are two stable steady states, one where the coalition is horizontal, with $\bar{k}_{S}=\frac{\theta}{\lambda}$ and another one where the coalition is vertical, with $\underline{k}_{S}=\mu \frac{\theta}{\lambda}$. Inequality is higher and the redistribution rate is lower in $\underline{k}_{S}$ than in $\bar{k}_{S}$. Furthermore, in that case,

i) if $k_{0}>\frac{\theta}{\lambda \mu} \frac{1}{R^{2}}$ inequality converges to $\bar{k}_{S}$ and, ii) otherwise, inequality converges to $\underline{k}_{S}$.

3) If $\mu R^{2}<1$, inequality converges to a unique steady state where the coalition is vertical and where asset inequality is $\underline{k}_{S}=\mu \frac{\theta}{\lambda}$.

Proof. Results concerning the horizontal coalition steady state are straightforward. For the vertical coalition, the steady state is $\underline{k}_{S}$ such that $t\left(\underline{k}_{S}\right)=0$; its value can be directly derived from 3 . This steady state is stable because the derivative of $k_{t}+t\left(k_{t}\right)=\sqrt{\mu k_{t} \frac{\theta}{\lambda}}$ with respect to $k_{t}$, evaluated at $\underline{k}_{S}$ equals $\frac{1}{2}<1$.

The vertical (horizontal) coalition steady state exists if $f\left(k_{t}\right)$ evaluated at $k^{*}$ corresponding to the vertical (horizontal) coalition is lower (higher) than $k^{*}$. Solving these inequalities yields directly the corresponding results.

Proposition 2 states that there can be one or two stable steady states, depending on the parameters of the model. One steady state implies a horizontal coalition where inequality is low and redistribution is high. The other steady state implies 
a vertical coalition where inequality is high and redistribution is low. The steady state with a vertical coalition exists only when the rate of return is sufficiently low, and the poor suffer sufficiently high losses in the first period of the horizontal coalition $(\mu$ low). In that case, the poor are willing to give up all redistribution in the vertical coalition while the rich find it worth to sacrifice the higher investment opportunities that the horizontal coalition would bring. The steady state with a horizontal coalition is assured to exist in the reverse case. There are configurations of the parameters (when $1<\frac{1}{\mu R}<R$ ), where the two steady states coexist. Figure 1 plots the function $f\left(k_{t}\right)$ depicting such a situation.

Figure 1

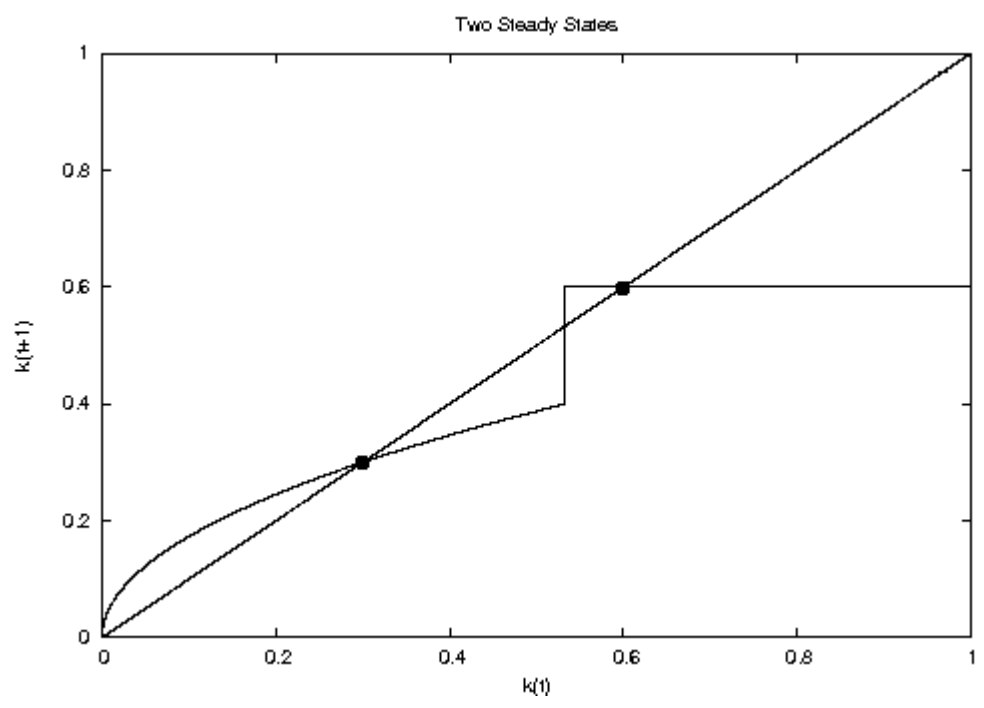

It is of particular interest to study the ways in which a vertical coalition with high inequality may break, paving the way for a transition towards a horizontal coalition with low inequality. There are two particularly interesting cases in which this may occur in this model, which are depicted in Figures 2 and 3. Figure 2 considers the effect of an increase in $R$, while Figure 3 depicts the effect of an increase in $\mu$ and $\theta$, of the same proportion. 
Figure 2

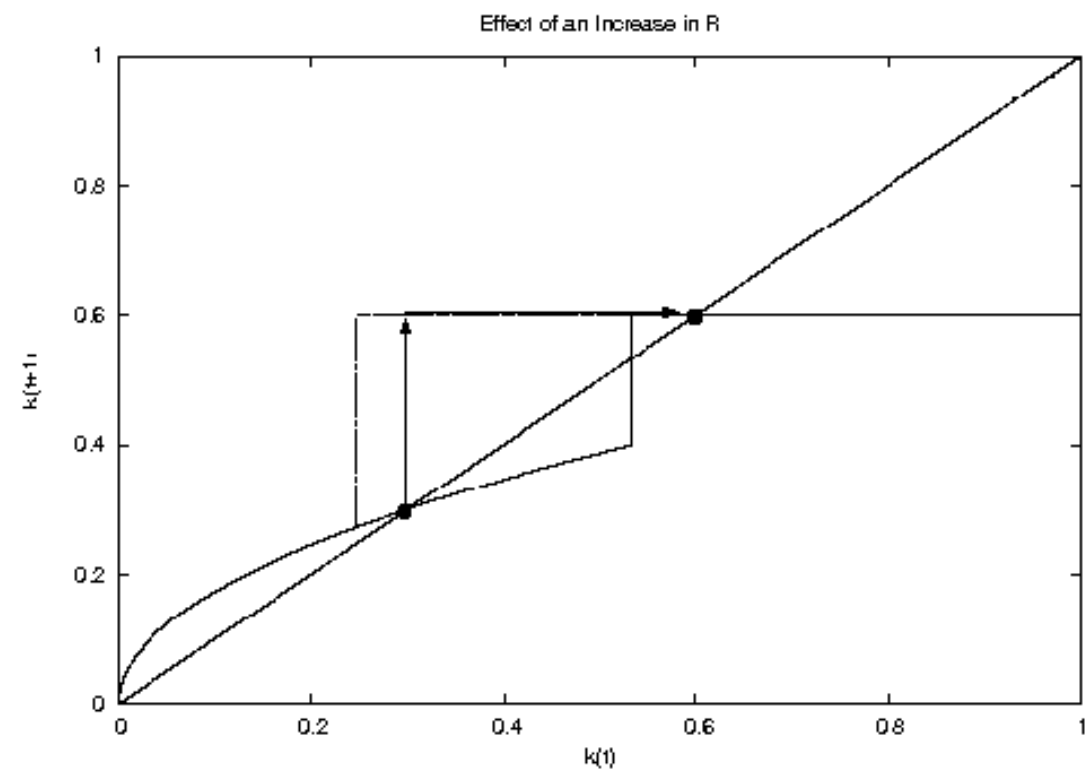

Suppose the initial situation is the vertical coalition steady state $\underline{k}_{S}$. If the rate of return increases, the threshold $\frac{\theta}{\lambda \mu} \frac{1}{R^{2}}$ shifts leftwards. The elite breaks the vertical social contract in order to exploit the benefits from the higher investment returns that the horizontal coalition enables. The poor are then lead to organize. They suffer a painful transition in the process, but eventually reap the benefits from organization and obtain a high level of redistribution, which remains thereafter.

Figure 3

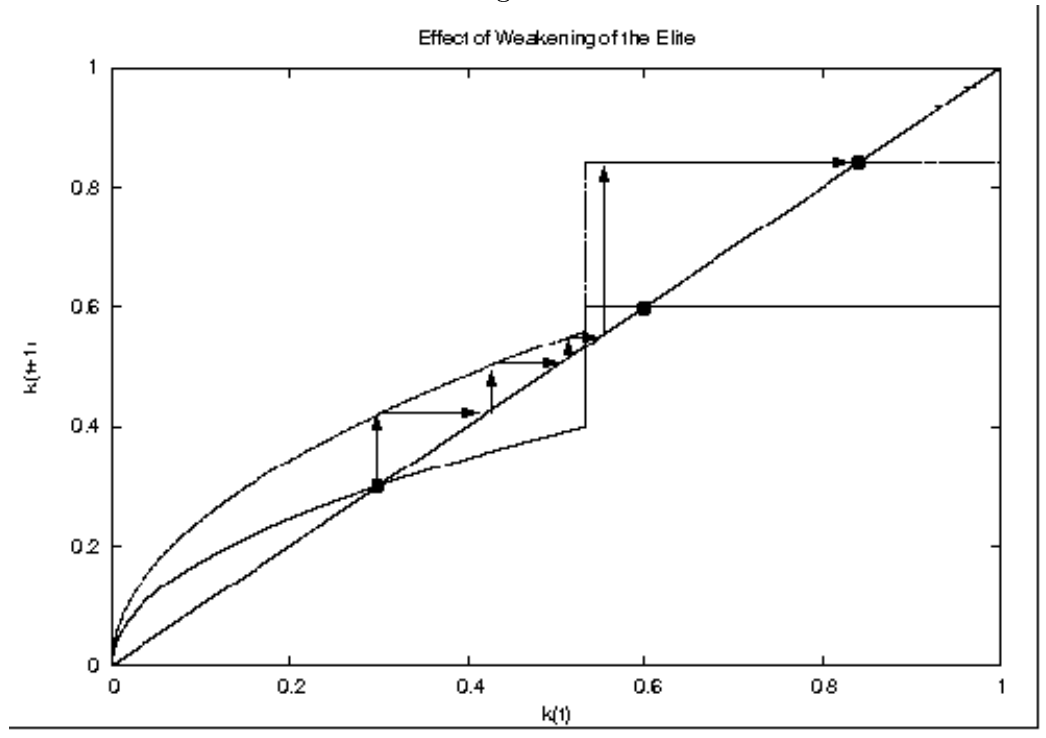


If, in contrast, $\mu$ and $\theta$ increase in the same proportions, the transition is different. The threshold $\frac{\theta}{\lambda \mu} \frac{1}{R^{2}}$ does not move, but the left piece of $f\left(k_{t}\right)$ shifts upwards. This type of increase captures a situation here the elite has been weakened for exogenous reasons, so that a horizontal coalition brings more benefits to the poor in the two periods. The poor, in that way, are able to extract more transfers from the rich while remaining in the vertical coalition. These transfers, however, make their offsprings richer so that consumption fluctuations become less painful and the horizontal coalition more attractive. Eventually, the horizontal coalition is worth undertaking and inequality becomes permanently reduced.

\section{DisCUSSION}

This section discusses some stylized facts concerning inequality, redistribution and coalitions in the light of the model presented above. It compares, first, Latin America, and to a lesser extent the Middle East and North Africa (MENA), with Western European Countries. In a similar vein, preindustrial Europe is contrasted with contemporary Europe, using the case of England as an illustration. This section aims at illustrating that the the factors considered in this paper are relevant for understanding inequality persistence. However, it does not, in any way, claim that these are the only relevant factors. Likewise, it does not aim at providing a review on these varied and enormous topics, but just at providing some examples that illustrate the main points.

4.1. Latin America and MENA vs. Western Europe. The model presented can help explaining the persistent differences in inequality observed between certain world regions. Latin America and, to a lesser extent, the Middle East and North Africa (MENA), are considered regions with high degrees of economic inequality. Dollar and Kraay (2001), for instance, estimate an average Gini coefficient in the MENA of 9 percentage points (pp.) higher than in the OECD countries over the period 1950 to 1999; the figure for Latin America is $15 \mathrm{pp}$. The aforementioned Frankema Gini coefficients for land inequality yield comparable results, with a difference between the MENA and Western Europe of 8 pp., and of $18 \mathrm{pp}$. for Latin America. For the case of Latin America, redistribution levels also appear to be substantially lower than in developed countries. While the latter collected in taxes over the 90s, on average, 29 percent of GDP, the figure for Latin America for that period was almost half, 15 percent. This difference was mainly accounted for by individual income taxes, usually the most redistributive component of taxation, and by social security payments, associated to the typically redistributive welfare state (see De Ferranti et al. (2003)).

These differences in inequality and redistribution coexist with substantial differences in the degree of worker's organization. Although measurable indicators are elusive, scholars of the region offer a clear picture: horizontal organization has traditionally been less prominent in Latin America and the MENA than it has been in Western Europe. De Ferranti et al. (2003), argue that, in Latin America, relations between the elite and the poor are characterized by vertical arrangements, either formal (corporatist) or informal (clientelist). In both cases, the arrangement is characterized by an elite offer of favors and/ or benefits, in exchange for political support and, ultimately, for maintaining the existing social order. Compared to the European experience, the organized working class in Latin America has typically been considered as historically weak and divided. At times, the working classes did 
unite for the pursuit of particular reforms, but these moments of unity where temporary, and the organized labor movement appears not to have been particularly prominent in the process (Peloso (2003)). In the analysis of political systems in the MENA, the word "corporatism" is often encountered as well, and patron-client relations appear to be pervasive. Until recently, the political situation in the region was characterized by the concept of "Arab social contract", whereby rulers offered subsidies and government employment to the masses in exchange for quiescence and lack of political agitation. Working class movements have barely had popular support in the MENA region. Instead, "vertical" arrangements cutting across class lines, such as nationalist movements or ethnic-based groups have been the norm (Ayubi (1995) and Richards and Waterbury (1996)).

In this way, the MENA region and, above all, Latin America, can be thought of as corresponding to the high-inequality steady state of the model, where the type of coalition formed is vertical. Contemporary Western Europe, in contrast, would correspond to the low inequality steady state with a horizontal coalition.

In recent decades, the two regions have undergone important social changes. In Latin America, the pro-market, budget-cutting 90s appear to be giving way to left-leaning governments in important countries of the region; horizontal coalitions likewise appear to have become more prominent in recent times (Shefner (2001)). Similarly, the 90s in the MENA saw an important challenge for the "Arab social contract", with many countries suffering violent riots and protests. Interestingly, these developments are typically attributed to austerity measures imposed by international organizations in order to provide credit. In that sense, the insights of this paper can prove useful, particularly, regarding the link between vertical coalitions and the characteristics of alternative investments opportunities for the elite: credit restrictions, by rising the value of present wealth in the $80 \mathrm{~s}$, would induce the elites to cut the transfers associated to the vertical social contract, leading in this way horizontal organizations to become more prominent. While this seems to have been largely the case in Latin America, it is interesting to notice, however, that the most prominent type of coalition that has aroused recently in Middle Eastern countries, the Islamists, do not aim specifically at increasing redistribution.

4.2. Modern England. Recent studies have provided evidence on inequality and redistribution in England from the eighteenth to the twentieth centuries (see Lindert (2004) for redistribution and Lindert (2000) for a review of the studies on inequality). Some controversy remains in the assessment of the trends in inequality, particularly, regarding whether inequality (of earnings as well as income and wealth) rose or not before the end of the nineteenth century. What seems uncontroversial, however, is that both income and wealth inequality gradually fell from the beginning of the twentieth century onwards (see Lindert (2000)). ${ }^{4}$ This gradual fall in inequality coincides with the start of a substantial upward trend in redistribution. Besides a particular episode in the beginning of the nineteenth century, social spending in England had been essentially negligible up to the end of the nineteenth century (Lindert 2004). From then on, matters started to change. As mentioned in Acemoglu and Robinson (2000), the share of taxes in GDP rose dramatically towards the end of the nineteenth century and so did its progressivity. Moreover,

\footnotetext{
${ }^{4} \mathrm{Up}$ to, obviously, the well documented rise in inequality during the 1980 's.
} 
it is precisely around this period where the educational system became open to the masses and public expenditures per pupil started accelerating (Lindert (2004)).

How these trends came into being is obviously the consequence of the interplay of many forces. Here, some forces are isolated yielding a consistent narrative. Up to the nineteenth century, a social contract whereby the elite insured the poor and transferred a modest amounts of resources was in place. This social contract took the form, among others, of customary rights of the poor (Quigley (1996), Hobsbawm and Rude (1969)), of price controls of bread in order to isolate the poor from variable food prices (Davies (2004), Thompson (1971)) and of "old poor laws" which, to a certain extent, assured the survival of the poor. These measures aimed partly at maintaining the existing social order. For instance, Van Leuween (1994), discussing the role of poor relief in preindustrial Europe, argues: "Socially, European elites endeavored to stabilize the existing social order by means of poor relief. [...] the well to do were under an obligation to assist the poor and the latter had a duty to accept the world as it was" (p. 593). This system of duties and obligations characterizes a "traditional social contract" or, in the terminology used in the model, a vertical coalition. Indeed, while this system was in place, the poor remained unorganized.

The beginning of the nineteenth century witnessed the culmination of the process of deterioration of the traditional social contract. Key protecting laws were definitively repealed. The enclosure movement was at its heights bringing forward the process of privatization of the commons which, by 1832, was completed. Crucially, the poor relief system was transformed by the New Poor Law, enacted in 1834. The New Poor Law centralized the administration of relief, made conditions of eligibility more stringent and set up mechanisms in order to deter demand for relief. Meanwhile, spending in poor relief fell substantially (Lindert (2004)). Polany (1954) considered the enactment of New Poor Law in 1834 as the symbol of the demise of the traditional social contract and this view appears to be largely shared by more recent studies (Dunkley (1981), Mandler (1987)).

This same time period, the late eighteenth and early nineteenth century, is precisely the one chosen by Thompson in his influential work on The Making of the English Working Class (1979). Thompson studies the variety of factors and experiences leading to the configuration of the English working class. The importance attributed to the collapse of the traditional social contract for this making is best illustrated by the figure of William Cobbett. William Cobbett was a radical journalist, who later got elected to parliament. His pamphlets and newsletters had remarkably high circulation from the end of the Napoleonic Wars until the 1830's. Indeed, he is considered to have been a key figure in bringing about a Radical consensus (Thompson (1979)). The radical criticism of Cobbett turned heavily against "Old Corruption" (the political elite of the time) and in defense of the traditional rights of labouring people. On these latter, it is worth quoting him extensively:

Among these rights was, the right to live in the country of our birth; the right to have a living out of the land of our birth in exchange for our labour duly and honestly performed; the right, case we fell into distress, to have our wants sufficiently relieved out of the produce of the land, whether that distress arose from sickness, from decrepitude, from old age, or from inability to find employment. [...] For a thousand years, necessity was relieved out 
of the produce of the Tithes. When the Tithes were taken away by the aristocracy, and by them kept to themselves, or given wholly to the parsons, provision was made out of the land, as compensation for what had been taken away. That compensation was given in the rates as settled by the poor-law. The taking away of those rates was to violate the agreement, which gave as much right to receive in case of need, as it left the landowner a right to his rent. ${ }^{5}$

This interpretation of the past was highly idealistic. What is important to note here is that these ideas did connect with the experiences of labouring people and that appears to have been relevant for the formation of a genuinely horizontally organized (working class) movement (Thompson 1979).

In the late 1830's, soon after the New Poor Law was enacted, what is regarded as the first organized English working class movement, Chartism, came into being. It did not demand the return to a traditional social order, but parliamentary reform, including universal suffrage. Although the movement failed in the mid century, it is considered to have set the stage for future working class organized movements and demands. An important part of these demands were eventually met and became law. Notably, the franchise was gradually extended and, by 1884, already included substantial working class representation. From that point, the degree of redistribution did not take long to rise and the level of inequality, to decrease (see Acemoglu and Robinson (2000) and Lindert (2004)).

The above quote of William Cobbett illustrates well the contemporary view that the "traditional social contract" had been broken by the elite, by failing to honour the obligations it imposed on them. In that respect, it is interesting to notice that this occurred in the midst of the industrial revolution, where technological improvements made investments more profitable. This transformation, hence, illustrates well the role of the rate of return in the model. The alternative way in which the demise of the "traditional social contract" gives way to worker organization in the model can be illustrated by contrasting the English experience with that of Germany. In Germany, the Napoleonic occupation and the 1848 march revolution (both absent in England), eroded the legitimacy and the power of the elite. After unification, power was centralized and the state grew stronger. Junkers and heavy industrialists did benefit from the state intervention, but their "marriage of iron and rye", seems to have been overplayed, and the chancellor did indeed use "divide and rule" strategies over the elite (Blackbourn (1997)). The insights of the model can thus make sense of the well known instauration of a social security system in the 1880 s that aimed to halt the labor movement, but patently failed to do so. In that way, the relative weakness of the elite in Germany may help explain its different path towards working class organization compared to that of England.

\section{Concluding Remarks}

Social contracts are a relevant factor for understanding the persistent inequality differences across regions of the world as well as for the remarkable evolution of inequality in Western Europe. This paper shows that the interactions between inequality and the type of coalition formed in a society can give rise to self-sustained social contracts where inequality persists: because the poor take time to organize,

${ }^{5}$ Tour of Scotland (1833), cited in EP Thompson (1979), pp. 836-837. 
when inequality is high, the poor are vulnerable to consumption fluctuations and are willing to give up substantial redistribution in order to be protected from these. For the rich, this "traditional social contract" is an investment. If the rate of return to alternative investments rises substantially or the elite becomes weakened, this traditional social contract may break, paving the way for working class organization and a permanent decrease in inequality.

These insights were shown using a simple model. For the sake of tractability and clarity, several simplifying assumptions were made. Indeed, a full understanding of the complexities of social contracts was well beyond the scope of this paper. It is worth mentioning certain elements not considered in the model that stand out for their importance, and that deserve (and are indeed receiving in the literature) further attention. First, individual heterogeneity was restricted to two types of individuals holding different amounts of wealth. The important role of the middle classes for the type of coalition formed (stressed, for instance, in Luebbert (1987) for the interwar period in Europe), needs to be addressed. Second, the model has focused on co-optation, leaving aside the other crucial element used by elites and rulers to maintain the existing social order: repression. Third, as the case of England shows, insurance is a particularly important element of traditional social contracts. Acknowledging the role of insurance can help shedding light into another important component in the transformation of the social contract in Europe related to the type of protest: from riots to organized protest. As certain authors have noted (Thompson (1971), Rude (1964)), riots can be understood as ways for the poor to enforce the traditional social contract. Finally, as the experience in the MENA shows, the type of coalitions allowed to form needs to be expanded. In the MENA, tribal groups have traditionally played a crucial political role and the strongest organized opposition are Islamist movements appealing to religious identity rather than class. The emergence of identity-based movements and its interactions with inequality need to be further studied to account for additional types of social contracts. Studying theoretically all these mechanisms at a moment where efforts are being made to gather empirical evidence on inequality back into the distant past (Piketty (2005), Bourguignon and Morrison (2002)) will greatly enhance our understanding of the dynamics of inequality over the long haul.

Nevertheless, the model in this paper can give useful insights for policy. First, as the experience in Latin America shows, elections are not enough for achieving a significant decrease in inequality. The model of this paper points at the importance of aversion to consumption fluctuations that extreme poverty generates. In that respect, the policy followed by the World Bank and certain governments (for instance, those of the European Nordic countries) in channeling their aid towards the poorest of the poor, is well targeted. Further measures should include, according to the model, access to financial markets by the poor. This would help smoothing their consumption and, additionally, give them access to investment opportunities as the rich have. Possibly the most important measure of all would be an appropriate working of the rule of law. This is relevant to ensure a credible commitment for the part of the elites, thus enabling the formation of efficient vertical coalitions. Particular attention should be paid on eroding the power of the local elites, which tend to be more easily arbitrary.

Achieving these goals is not straightforward for external actors, since their partners are, almost inevitably, the elites. This paper points at another problem in this 
respect: the poor may actually rally together with the elites against externallyadvocated reforms. This may be the case even if these reforms may actually benefit the poor in the long run. Social contracts indeed have a rationale and, in this paper, that rationale is the painful transition that the poor would suffer on the way to a more beneficial social contract. Particular importance, therefore, needs to be attached to safety nets in transitions as well as to a gradual enhancement of civil society organizations.

\section{REFERENCES}

[1] Acemoglu and Robinson (2000). "Why did the West Extend the Franchise? Democracy, Inequality and Growth in Historical Perspective." Quarterly Journal of Economics 115, pp. 1167-99.

[2] Alesina and Rodrick (1994). "Distributive Politics and Economic Growth." Quarterly Journal of Economics 109, pp. 465-90.

[3] Benabou (2000). "Unequal Societies: Income Distribution and the Social Contract." American Economic Review 90, pp. 96-129.

[4] Bertocchi, G. and M. Spagat 2001. "The Politics of Cooptation", Journal of Comparative Economics 29 (4): 591-607.

[5] Bertola and Koeniger (2005). "Consumption Smoothing and the Structure of Labor and Credit Markets". Unpublished manuscript.

[6] Blaug (1963). "The Myth of the Old Poor Law and the Making of the New." The Journal of Economic History 23, pp. 151-84.

[7] Block and Summers (2003). "In the Shadow of Speenhamland: Social Policy and the Old Poor Law." Politics \& Society 31 pp. 283-323.

[8] Conley and Tiemimi (2001). "Endogenous Enfranchisement when Groups' Preferences Conflict." Journal of Political Economy 109, pp. 79-102.

[9] Davies (2004). "Baking for the common good: A reassessment of the assize of bread in Medieval England." Economic History Review 57, pp. 465-502.

[10] Dunkley (1981). "Whigs and Paupers: The Reform of the English Poor Laws, 1830-1834." The Journal of British Studies 20, pp. 124-149.

[11] De Mello and Tiongson (2003). "Income Inequality and Redistributive Government Spending". IMF Working Paper 314.

[12] De Ferranti, Perry, Ferreira, Walton (2003). Inequality in Latin America 8 the Caribbean: Breaking with History? World Bank.

[13] Hobsbawm and Rude (1969). Captain Swing. Phoenix Press (2001). London, UK.

[14] Jack and Lagunoff (2004). "Dynamic Enfranchisement". Mimeo.

[15] Justman and Gradstein (1999). "The Industrial Revolution, Political Transition and the Subsequent Decline in Inequality in 19th Century Britain." Explorations in Economic History 36. pp 109-27.

[16] Lindert (2004). Growing Public: Social Spending and Economic Growth Since the Eighteenth Century. Cambridge University Press. Cambridge, UK.

[17] Lindert (2000). "Three Centuries of Inequality in Britain and America." in Atkinson and Bourguignon (Eds.) Handbook of Income Distribution. North Holland. Amsterdam.

[18] Mandler (1987). "The Making of the New Poor Law Redidivus." Past and Present 117, pp. $131-57$.

[19] Meltzer and Richard (1981). "A Rational Theory of the Size of Government." Journal of Political Economy 89 pp. 914-27.

[20] Milanovic (2003). "Is inequality in Africa really different?" mimeo. World Bank.

[21] Persson and Tabellini (1994), Is Inequality Harmful for Growth? American Economic Review 84 , pp. $600-21$.

[22] Polany (1954). The Great Transformation: The Political and Economic Origins of Our Time. Beacon Press. Boston. (First edition 1944)

[23] Putterman, Roemer and Silvestre (1998). "Does Egalitarianism Have a future." Journal of Economic Literature 36, pp. 861-902.

[24] Quigley (1996). "Five Hundred Years of English Poor Laws, 1349-1834: Regulating the Working and the Non Working Poor." Akron Law Review 30, pp.73-128. 
englishINEQUALITY PERSISTENCE THROUGH VERTICAL VS. HORIZONTAL COALITION\$7

[25] Richards and Waterbury (1996). A Political Economy of the Middle East. Boulder, Colo : Westview Press.

[26] Rodriguez (2004). "Inequality, Redistribution and Rent-Seeking." Economics and Politics 16, pp. 286-320

[27] Saint Paul (2001). "The Dynamics of Exclusion and Fiscal Conservatism." Review of Economic Dynamics 4, pp. 275-302.

[28] Saint Paul and Verdier (1996). "Inequality, redistribution and growth: A challenge to the conventional political economy approach." European Economic Review 40, pp. 719-28.

[29] Saint Paul and Verdier (1997). "Power, Distributive Conflicts, and Multiple Growth Paths." Journal of Economic Growth 2, pp. 155-68.

[30] Shefner (2001). "Coalitions and Clientelism in Mexico". Theory and Society 30, pp. 593-628.

[31] Thompson, E.P. (1971). "The Moral Economy of the English Crowd in the Eighteenth Century." Past and Present 50, pp. 76-136.

[32] Thompson, E.P. (1979). The Making of the English Working Class. Penguin. London. (First edition 1963).

[33] Van Leuween (1994). "Logic of Charity: Poor Relief in Preindustrial Europe." Journal of Interdisciplinary History 24, pp. 589-613. 